\title{
New Era of Oral Anticoagulation for Japanese Non-Valvular Atrial Fibrillation Patients
}

Teruyuki Hirano, MD

W arfarin, once the only drug used orally to prevent thromboembolic events in patients with non-valvular atrial fibrillation (NVAF), has now been replaced, more rapidly than expected, by new-generation drugs called "novel" or "non-vitamin K antagonist" oral anticoagulants (NOACs). ${ }^{1}$ The NOACs target specific coagulation enzymes, either thrombin or factor Xa, whereas warfarin lowers the levels of multiple coagulation factors (II, VII, IX and X) by inhibiting vitamin $\mathrm{K}$ supply. Though the target differs between the direct thrombin inhibitor, dabigatran, and Xa inhibitors such as rivaroxaban, apixaban, and edoxaban, a low incidence of major bleeding and intracranial hemorrhage (ICH) compared with warfarin is a notable common feature of both classes of drugs as demonstrated by large clinical trials such as RE-LY, ROCKET-AF, ARISTOTLE, and ENGAGE-AF TIMI48. ${ }^{2-5}$ Of the 4 NOACs, dabigatran was the first to be commercially available, since 2011 in Japan, and thus began the new era of anticoagulation therapy.

\section{Article p 1335}

In this issue of the Journal, Komori et $\mathrm{al}^{6}$ describe $9 \mathrm{ICHs}$ that occurred in 8 patients treated with dabigatran. The purpose of their survey was to elucidate the clinical characteristics of

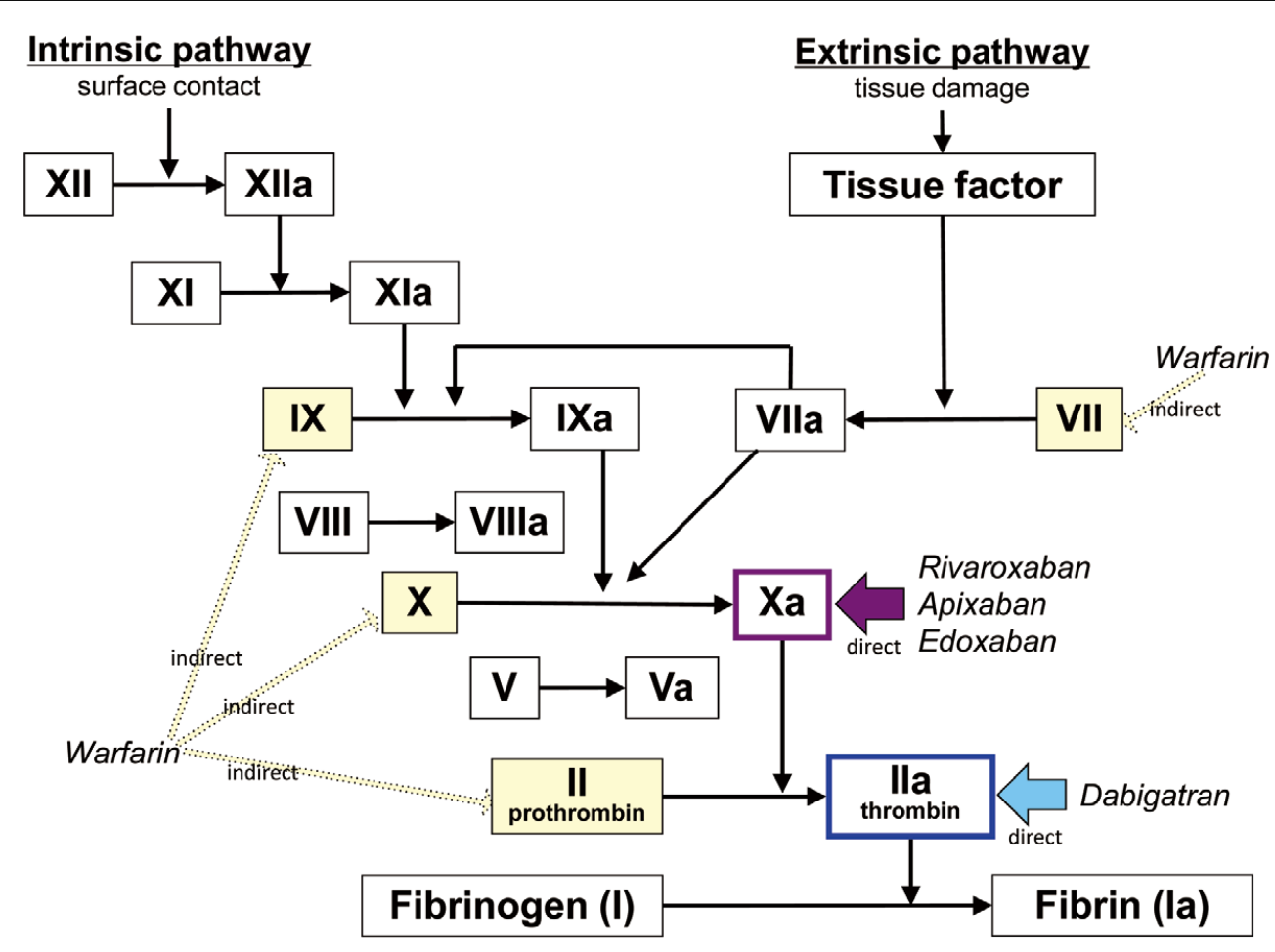

Figure 1. Coagulation cascade and the target sites blocked either directly or indirectly by oral anticoagulants.

The opinions expressed in this article are not necessarily those of the editors or of the Japanese Circulation Society.

Received April 15, 2014; accepted April 15, 2014; released online May 7, 2014

Department of Neurology, Faculty of Medicine, Oita University, Yufu, Japan

Mailing address: Teruyuki Hirano, MD, Associate Professor, Department of Neurology, Faculty of Medicine, Oita University, 1-1 Idaigaoka,

Hasama, Yufu 879-5593, Japan. E-mail: terry12@oita-u.ac.jp

ISSN-1346-9843 doi:10.1253/circj.CJ-14-0454

All rights are reserved to the Japanese Circulation Society. For permissions, please e-mail: cj@j-circ.or.jp 


\section{Coagulation cascade}

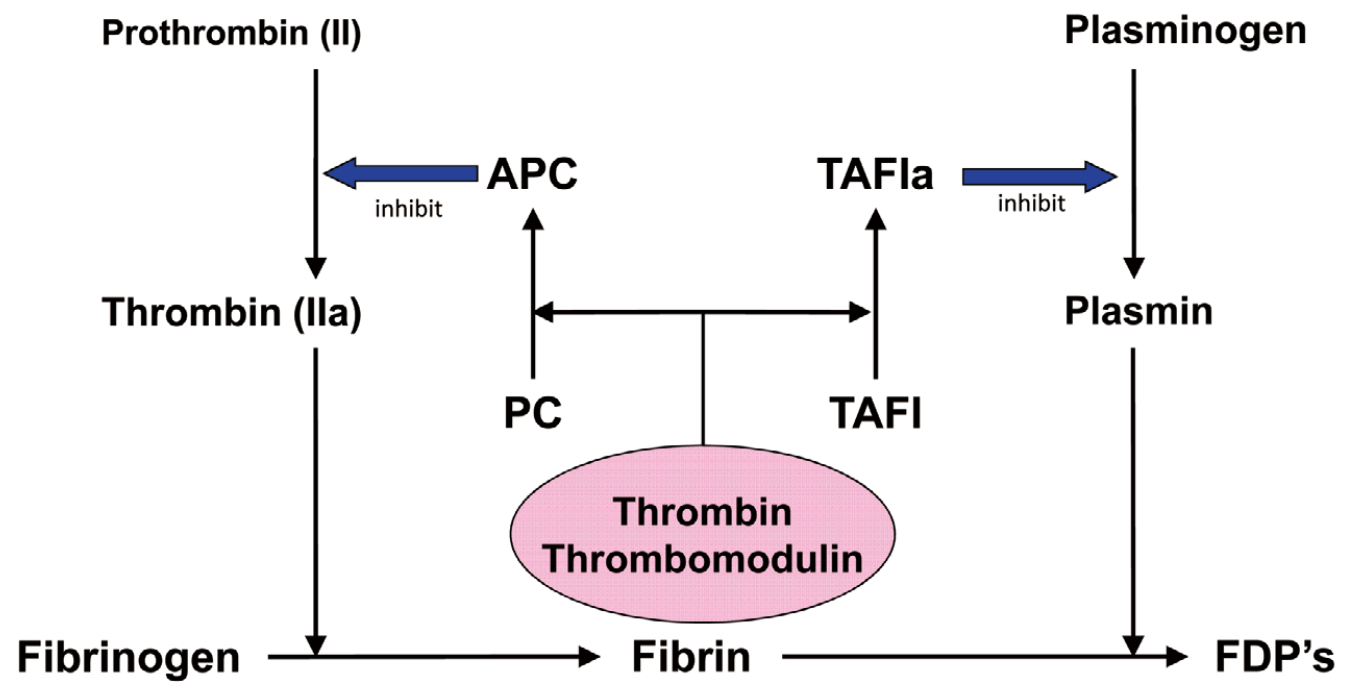

Figure 2. Balance of coagulation and fibrinolytic cascades and the role of thrombin. APC, activated protein C; PC, protein C; FDP's, fibrin degradation products; TAFI, thrombin activated fibrinolysis inhibitor. (Modified with permission from Nesheim M. ${ }^{13}$ )

ICH during dabigatran treatment. Their key messages are: the extent of the ICH is small to moderate, does not readily expand, and the outcome is good. Although this survey had the inevitable selection bias related to its retrospective and hospitalbased nature, the number of ICHs was low among the participating high-volume stroke centers in Kyushu, Japan. Lacking information on how many patients in their region received this drug, an estimate of $\mathrm{ICH}$ incidence would be of most interest, though that was not the purpose of the survey.

During the first 6-month period from March 2011, dabigatran was estimated to be used in approximately 70,000 patients with NVAF in Japan. Post-marketing surveillance in the 6 months ${ }^{7}$ disclosed 29 cases of severe $\mathrm{ICH}$, including 8 patients with cerebral (parenchymal) hemorrhage, 5 with hemorrhagic infarction, and 1 each of intraventricular hemorrhage, ICH, cerebellar hemorrhage, hemorrhagic stroke, and pituitary bleeding. The remaining patients suffered from subdural hematoma in 8 cases and subarachnoid hemorrhage in 3. Among them, dabigatran was used as secondary prevention in 14, and 6 patients were administered the drug within 14 days of a previous stroke. Fatal outcome was reported for 3 patients, 1 each from parenchymal hemorrhage, subdural hematoma and subarachnoid hemorrhage. In contrast, despite strict intensity control of prothrombin time, the incidence of major hemorrhage with warfarin remains high even in recent studies (eg, 1.5-4.1\%). ${ }^{8}$ These data obtained from real-world experience are in accord with global experience ${ }^{2}$ and the Japanese subanalysis ${ }^{9}$ of RE-LY. The low incidence of $\mathrm{ICH}$ even in high-age groups ${ }^{10}$ is the most striking feature of the new-generation anticoagulants, that is, the NOACs' era.

One point to be emphasized about the present study is that only 2 parenchymal hemorrhages were observed. The authors relate this phenomenon to the preservation of factor VIIa, which initiates the coagulation cascade by complexing with tissue factor (Figure 1). The brain is one of the organs that have an abundance of tissue factor. Thus, microbleeds from minor in- jury of the brain vasculature could be stopped by the complex of tissue factor and factor VIIa. ${ }^{11}$ Such a mechanism is not activated during warfarin treatment because of the shortage of factor VIIa, and thus results in enlargement of hematoma. ${ }^{12}$ NOACs' short half-life with a blood concentration of the peakand-trough pattern also contribute to its favorable clinical features. Should these be the main characteristics of not only with dabigatran, but also other factor Xa inhibitors, their use would reduce the incidence of anticoagulation-related parenchymal hemorrhage.

Another possibility of the low ICH incidence reported by Komori et al is preservation of thrombin activatable fibrinolysis inhibitor (TAFI) and subsequent inhibition of fibrinolysis by TAFIa (Figure 2 ). ${ }^{13}$ In addition, the neuroprotective potential of another direct thrombin inhibitor, argatroban, has been observed in animal models. ${ }^{14}$ If these factors relate to the prevention of major bleeding and subsequent neurological deficit, the feature might be specific for direct thrombin inhibitors, including dabigatran.

The presented data are important as this is the first presentation of details of dabigatran-related ICH. At the same time, however, this study is also hypothesis generating. We need to elucidate the exact incidence of ICH, especially parenchymal hemorrhage, in real-world clinics by population-based studies. ${ }^{15}$ Is this low rate of parenchymal hemorrhage generalizable to all NOACs, or restricted to the direct thrombin inhibitor? With twice-daily, but not once-daily NOACs? We definitely need more experience and clinical studies.

\section{Disclosures}

Dr Hirano has received consultant fees from Boehringer-Ingelheim, and honoraria from Bayer, Sanofi, Mitsubishi-Tanabe, Boehringer-Ingelheim and Pfizer.

\section{References}

1. Husted S, De Caterina R, Andreotti F, Arnesen H, Bachmann F, 
Huber K, et al. Non-vitamin K antagonist oral anticoagulants (NOACs): No longer new or novel. Thromb Haemost 2014 March 21, doi:10.1160/TH14-03-0228.

2. Connolly SJ, Ezekowitz MD, Yusuf S, Eikelboom J, Oldgren J, Parekh A, et al. Dabigatran versus warfarin in patients with atrial fibrillation. N Engl J Med 2009; 361: 1139-1151.

3. Patel MR, Mahaffey KW, Garg J, Pan G, Singer DE, Hacke W, et al Rivaroxaban versus warfarin in nonvalvular atrial fibrillation. $N$ Engl J Med 2011; 365: 883-891.

4. Granger CB, Alexander JH, McMurray JJ, Lopes RD, Hylek EM, Hanna M, et al. Apixaban versus warfarin in patients with atrial fibrillation. N Engl J Med 2011; 365: 981-992.

5. Giugliano RP, Ruff CT, Braunwald E, Murphy SA, Wiviott SD, Halperin JL, et al. Edoxaban versus warfarin in patients with atrial fibrillation. N Engl J Med 2013; 369: 2093-2104.

6. Komori M, Yasaka M, Kuboda K, Matsuoka H, Fujimoto S, Yoshida $\mathrm{M}$, et al. Intracranial hemorrhage during dabigatran treatment: Case series of eight patients. Circ J 2014; 78: 1335-1341.

7. http://www.bij-kusuri.jp/information/attach/pdf/pxa_cap_ info_201111.pdf (accessed April 13, 2014) (in Japanese).

8. Inoue H, Okumura K, Atarashi H, Yamashita T, Origasa H, Kumagai $\mathrm{N}$, et al. Target international normalized ratio values for preventing thromboembolic and hemorrhagic events in Japanese patients with non-valvular atrial fibrillation: Results of the J-RHYSTHM Registry. Circ J 2013; 77: 2264-2270.
9. Hori M, Connolly SJ, Ezekowitz MD, Reilly PA, Yusuf S, Wallentin L. Efficacy and safety of dabigatran vs. warfarin in patients with atrial fibrillation: Sub-analysis in Japanese population in RE-LY trial. Circ J 2011; 75: 800-805.

10. Eikelboom JW, Wallentin L, Connolly SJ, Ezekowitz M, Healey JS, Oldgren J, et al. Risk of bleeding with 2 doses of dabigatran compared with warfarin in older and younger patients with atrial fibrillation: An analysis of the randomized evaluation of long-term anticoagulant therapy (RE-LY) trial. Circulation 2011; 123: 2363-2372.

11. Wu X, Du Z, Yu J, Sun Y, Pei B, Lu X, et al. Activity of factor VII in patients with isolated blunt traumatic brain injury: Association with coagulopathy and progressive hemorrhagic injury. J Trauma Acute Care Surg 2014; 76: 114-120.

12. Yasaka M, Minematsu K, Naritomi H, Sakata T, Yamaguchi T. Predisposing factors for enlargement of intracerebral hemorrhage in patients treated with warfarin. Thromb Haemost 2003; 89: 278-283.

13. Nesheim M. Thrombin and fibrinolysis. Chest 2003; 124(Suppl): 33S-39S.

14. Lyden P, Pereira B, Chen B, Zhao L, Lamb J, Lei IF, et al. Direct thrombin inhibitor Argatroban reduces stroke damage in 2 different models. Stroke 2014; 45: 896-899.

15. Goto S, Hata J, Ninomiya T, Hirakawa Y, Nagata M, Mukai N, et al. Trends in the incidence and survival of intracerebral hemorrhage by its location in a Japanese community: The Hisayama study. Circ J 2014; 78: 403-409. 